\title{
RISKS ASSOCIATED TO PRESENT GEOMORPHOLOGIC PROCESSES IN THE STEMNIC (BUDA) RIVER BASIN
}

\section{Ioan Bojoagă $\breve{1}^{1}$}

Key words: risks, geomorphological processes, morphometric parameters, digital terrain model.

\begin{abstract}
The paper analyses the main geomorphologic processes in the Stemnic (Buda) river basin, conditioned by the joint action of several factors, among which are the lithological peculiarities and the nature of superficial deposits, morphometric characteristics, climate, vegetation type and structure, properties of the soil cover etc. The Stemnic river basin with an area of 15662.52 ha is characterized by its elongated shape (the maximum length is of $30.5 \mathrm{~km}$, maximum width of $8.5 \mathrm{~km}$ ), its relative lithological homogeneity, but also by a variety of superficial deposits (eluvium, diluvium, colluvium and proluvium, alluvium) and by a relief energy of significant values between $136 \mathrm{~m}$ and $10 \mathrm{~m}$ (mean value of $73 \mathrm{~m}$ ). Under these conditions, study area is characterized by a high degree of susceptibility to the occurrence of geomorphologic risk processes. For the morphometric and morphological analysis, we applied the method of the digital terrain model (DTM) with vectorisation of the contour lines on topographic maps with a scale of 1:5,000. In this paper we used indicators that highlight the particular frequency of landslides, especially in the upper and middle sectors, but the rather reduced frequency of deep erosion. Due to the satisfactory coverage of the ground with vegetation, the erosion reaction is differentiated, as it depends on the use of the land and the concentration of liquid flow on the slopes. Consequently, landslides of different ages, types and forms hold large surfaces in the basin (approx. 8\%), while surface erosion affects most areas of the slopes, but with different intensities depending on their use and on agricultural technologies.
\end{abstract}

\section{Introduction}

The studied area is located south of the Central Moldavian Plateau, between parallels $46^{\circ} 48^{\prime} 26^{\prime \prime}$ and $46^{\circ} 39^{\prime} 33^{\prime \prime}$ latitude north and meridians $27^{\circ} 18^{\prime} 34^{\prime \prime}$ and $27^{\circ} 40^{\prime} 04^{\prime \prime}$ longitude east, with a surface area of $15,662.52 \mathrm{ha}$. It is a fusiform river

1 “Al. I. Cuza” University of Iaşi, Faculty of Geography and Geology, Department of Geography, Bd. Carol I 20 A, 700505, Iaşi, Romania, nelu_bojoaga@yahoo.com 
basin, elongated from northwest to southeast with a length of $30.5 \mathrm{~km}$ and a maximum width of $8.5 \mathrm{~km}$.

The geological background of the area, which controls the geomorphological processes, is the Khersonian deposits, occupying a surface area of 10,483,07 ha, being a seam of sand, sandy clay, clay, followed by Basarabian deposits with 2735,71 ha, predominantly psammitic and the last two are of Meotian age, occupying a surface area of 787,69 ha, which starts with andesitic cinerea with intercalations of sand, marl and clay, respectively of quaternary age, with a surface area of 1068,34 ha, represented by alluvial meadows, terraces, eluvial, deluvial or colluvial glacis alteration deposits.

From a geomorphometric standpoint, the average altitude of the basin is of $229 \mathrm{~m}$, the minimum is of $94 \mathrm{~m}$, at the confluence of Stemnic River with Bârladul River, and the maximum is of $466 \mathrm{~m}$, in the Răzeşi Hill. The maximum relief energy in this case is of $372 \mathrm{~m}$. Overall, the altitudes between 200-250 m (3996,1 ha) are predominant, followed by altitudes between 150 and $200 \mathrm{~m}$ (3743,75 ha)

Another factor influencing the geomorphological processes is the declivity of the land. The gap $5-15^{\circ}$ represents most of the area $(71,3 \%, 10.755$ ha respectively). Very high gradients, of over $15^{\circ}$, and very small ones, under $1^{\circ}$, have lower shares $(5,2 \%)$.

As control factors in the development of geomorphological processes, the climatic conditions, especially rainfall, winds and temperatures are also required. Their aggression is given by extreme values. Thusly, torrential rains have very strong erosion impact expressed by a synthetic indicator called rain aggressiveness. The maximum quantity of rainfall in a 24 - hour period occurred in the summer months due to a convective and frontal activity at the Vaslui Weather Station on $22^{\text {nd }}$ June 1980, $91.1 \mathrm{~mm}$ rainfall and in Negreşti on $20^{\text {th }}$ August 1972 with 91.4 mm rainfall.

High wind speeds have an important role in the processes of wind erosion (deflation) higher in the cold season, when the soil cover not receive protective coating, and during dry periods, when the cohesion of elementary particles decreases greatly.

In terms of geomorphological processes, a special interest represents the transition from winter to spring, when alternating freeze-thaw prepares the material to be discharged through the leakage generated either by snowmelt or by spring rains (I. Ioniţă, 2000).

The groundwater located at depths of $5-15 \mathrm{~m}$ in the Khersonian deposit, sometimes exceeding 15-20 m, can participate in the suffusion process. The rivers (Stemnic, Fâstâca) have a significant geomorphological role because they evacuate the erosion material from the slopes. 
The natural vegetation has suffered anthropic alterations, as it was replaced by secondary vegetation or crops. As vegetal formations in the basin, the steppe is predominant at altitudes below $200 \mathrm{~m}$ and deciduous forests at higher altitudes.

Geomorphological processes occurring in the Stemnic River basin are: denudation due to rainfall, gullying, landslides, collapses, suffusion and subsidence, fluvial processes.

\section{Materials and methods}

The information for this study was obtained using the topographic maps scale 1: 5.000 , the database created by using the TNT Mips 69 software, all data being entered as vectors and then changed in raster format.

The working method consists in importing the topographic maps in the GIS software, after which they were georeferenced in the coordinate system Romania, stereo area 70, Datun Piscului Hill, with a reference ellipsoid the Krassovsky ellipsoid 1938-1940. The next step is to provide a vector layer of the contour lines and then, the extraction of the areas with landslides from the topographic maps.

Regarding the study of statistic data of climatic elements for the period 19682007, these were obtained from the Moldova Weather Stations and they were processed in the Microsoft Office Excel 2007 program.

The changes created by human intervention by faulty farming, overgrazing and deforestation contributed to the accelerated occurrence of geomorphological processes. To systematically analyse the occurrence intensity of certain geomorphological processes by establishing the vulnerability / susceptibility of the concerned area, we need information about the land use (Table 1).

Table 1. Percentage of different types of land use in the Stemnic river basin

\begin{tabular}{|l|c|c|}
\hline \multicolumn{1}{|c|}{ Use categories } & Area (ha) & Percentage (\%) \\
\hline Settlements & 1380,08 & 9,16 \\
\hline Arable land & 4212,71 & 31,93 \\
\hline Vineyards & 536,54 & 3,56 \\
\hline Orchards & 500,27 & 3,32 \\
\hline Secondary pastures & 1098,02 & 7,29 \\
\hline Lands with complex use & 1359,41 & 9,02 \\
\hline Lands with complex use alternating with natural pastures & 1437,32 & 9,54 \\
\hline Deciduous forests & 3645 & 24,19 \\
\hline Transition areas with bushes & 301,79 & 2,00 \\
\hline Total & 15662,52 & 100 \\
\hline
\end{tabular}




\section{Results and discussions}

The denudation due to rainfall and the surface erosion are two processes that play an important role in modelling the basin relief and consist in removing the fine particles in the upper layers of soils on slopes.

The denudation due to rainfall occurs when the falling rain drops hit the surface of the soil displacing the particles which are transported by air on distances less than 1.5 m (Ioniţă, 2000).

This process is important in that it prepares the material that can then be picked up by the surface runoff. Within the basin, the surface erosion occurs wherever there is the slightest slope, which may allow water drainage. The runoff on the slopes begins to take shape tending to form elementary streams scattered among the small irregularities of the terrain with depths up to 2-3 cm (Figure 1).

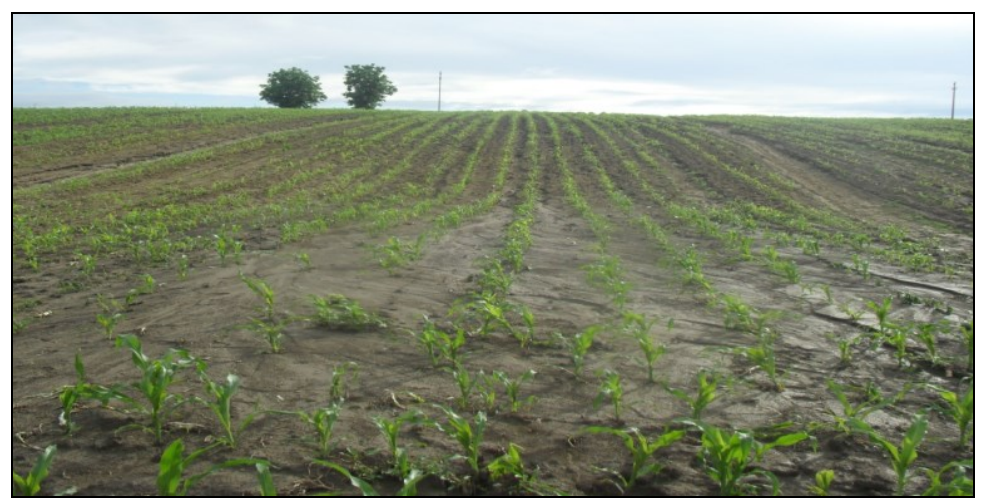

Fig. 1. Areolar erosion

Another form of surface erosion consists of grooves $(3-20 \mathrm{~cm})$ called troughs, being the result of the concentration of transient runoffs. It is estimated that runoffs and troughs are ephemeral; they disappear over time due to agricultural works.

In terms of the conditions that favour surface erosion, the agricultural lands located on slopes greater than 5\% are the most exposed surfaces (M. Moţoc, 1983). In this basin, such lands amount to 9919,8 ha. Besides the slope, the ablation is favoured by climate, the runoffs are characteristic to summer months. Within the basin, the most important role in the development and occurrence of surface erosion is played by the occupation and use of the land.

Arable lands have an area of 4212,71 ha and the surface erosion occurs on extensive areas, however, differentiated according to the type of cultivation or the stage of growth. The intensity of the process is more pronounced on steep lands, cultivated with corn, which does not provide erosion protection. For the lands in 
the Moldovian Plateau, given the degree of development of crops and the rain aggressiveness, the critical erosion season was established for the period $15^{\text {th }}-20^{\text {th }}$ May to $15^{\text {th }}-20^{\text {th }}$ June (I.Ioniţă, 2000).

The slopes affected by overgrazing have a total area of 2535,34 ha (16.83\%), where the surface erosion occurs with a greater intensity. The average annual surface erosion was estimated using the universal equation of erosion (USLE) adopted by M. Moţoc and others (1975). Based on zoning the total erosion on agricultural land, M. Moţoc classifies the river basin in the values class 20-30 t/ha/year.

Although it does not generate a specific microrelief and it is observed only on surfaces devoid of natural vegetation, the surface erosion (ablation) is the largest denudational process causing the greatest soil loss on agricultural lands.

The depth erosion is determined by the concentration of drainage in streams with a high flow rate and speed, in the context of an increase in kinetic energy of the liquid drainage and a lowering in the resistance of the substrate or vegetal protective cover (I. Ioniţă, 2000).

The field observations reveal the presence of some forms of depth erosion, represented by small ravines. They are spread to the upper base of some torrential bodies on the slopes where the presence of sands and the land inclination favour their occurrence. In many cases, these are fixed with plantations or partially covered with spontaneous vegetation.

The big ravines are less common compared to landslides, although loamy facies could favour the development of these forms of land degradation, especially on slopes. Of the two major categories of ravines, hills and valley bottom, the most common in within the basin is the first category, even though most of them are small and medium sized. However, large ravines also occur (Fig 2).

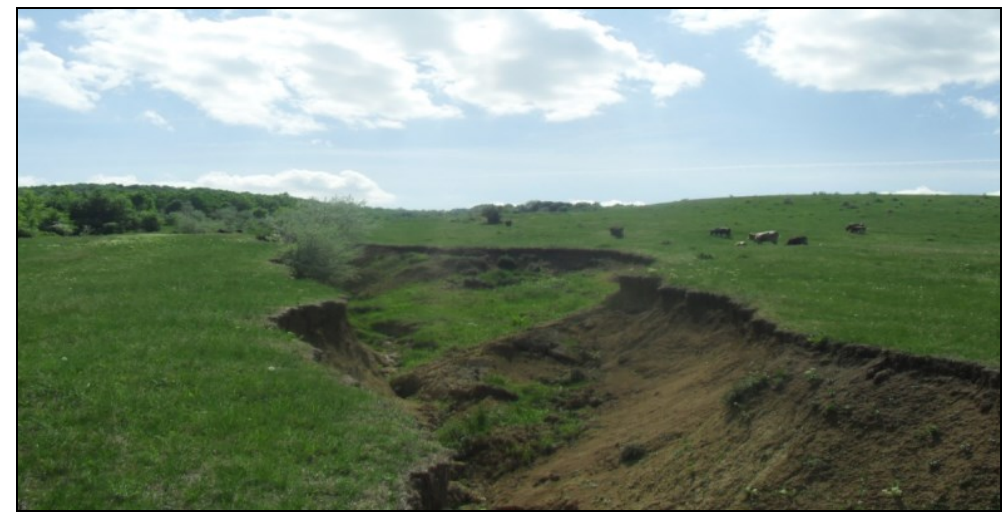

Fig. 2. Slope ravine in the middle sector of the Stemnic river basin 
Most frequently, access road and service roads are the ones favouring the concentration of the water on certain paths and are a significant cause in ravine forming in the hills. In other situations, ravines could also appear on hills with diluvium fragmented by mass displacement processes.

Landslides are the main mass displacement processes, gravity-caused processes and they are one of the major hazards that can cause damage to property or human damage.

In the Stemnic river basin, based on topographic maps 1: 5000, there are 58 active and semi-active sliding bodies with a reactivation potential. Their total surface is of 1278,60 (ca. 8\%). Their distribution is closely related to the presence of the cuesta relief, landslides having a high frequency on the cuesta fronts with a steeper slope and higher relief energy, with a clear section of permeable and impermeable lithological successions. In the lower part of the basin, landslides appear only on the right side of the Stemnic, with northern exposure, and on the left side of the Stemnic, with southern exposure, there is poorly fragmented cuestas reverse. In the middle and upper part of the basin, landslides are more common, taking into account the fact that the cuestas reverse is more evolved and that it is fragmented by a series of (re)consequent valleys that highlight a cuesta front with western exposure (Fig. 3).

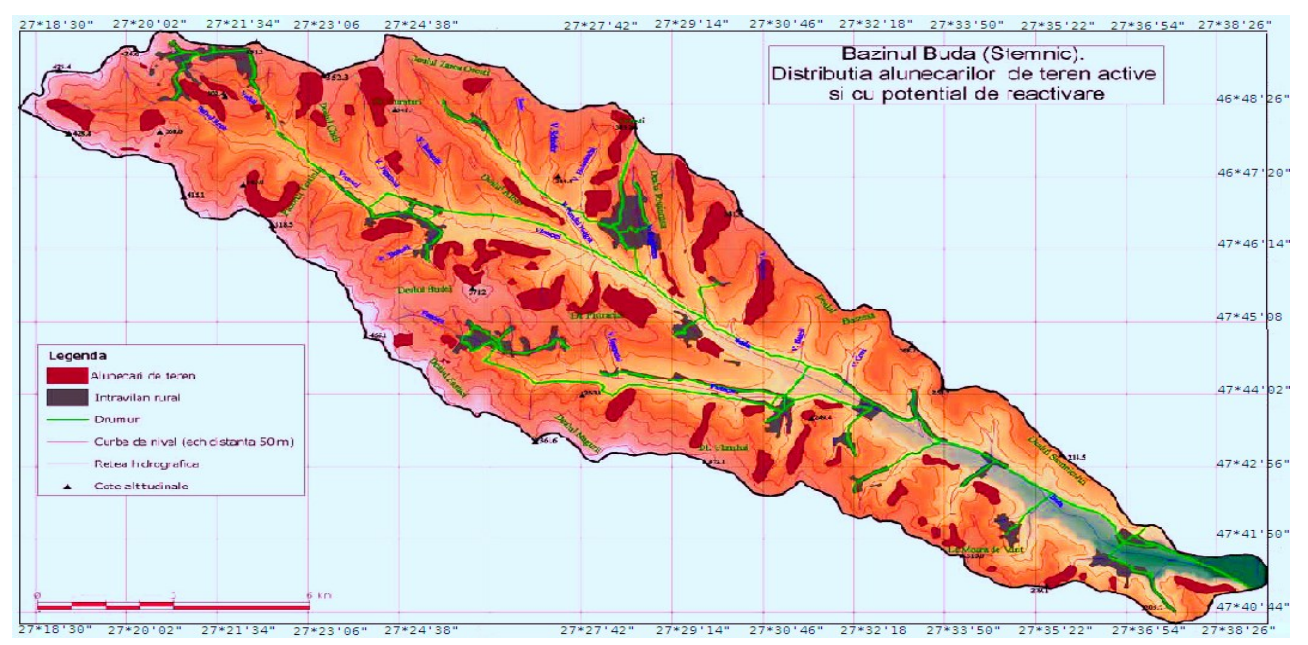

Fig. 3. Landslides in the Stemnic river basin

The approach of landslides in the Stemnic river basin takes into account the analysis of causal factors in order to determine the susceptibility of the slopes for the occurrence of such processes and the associated geomorphological risk. 
Geological conditions play an important role in the occurrence of processes associated with other causes.

As for the geology of the surface deposits, which have an important role in the genesis of landslides, we can mention the presence of Khersonian deposits that are the most frequent in the basin $(69,5 \%)$. These are represented by intercalations of clays, sandy clays, sands and loamy sands with a few hard intercalations. These formations concentrate the most sliding bodies. Pujină (2007) shows that the Khersonian geological deposits are the most susceptible to landslides, followed by Basarabian deposits and Meotian deposits.

The Basarabian formations are characterised primarily by the presence of some Psammitic deposits and secondarily of Pelitic deposits. They are less frequent in the basin $(18,15 \%)$ and concentrate fewer sliding bodies compared to the Khersonian deposits. Meotian deposits are the least frequent $(5,21 \%)$, as they are specific to interfluves where landslides cannot be triggered. The quaternary has a considerable development in the meadow of the main river and its tributaries; it does not represent an area of landslides in the basin.

The relief plays and important role in triggering landslides, interfering by a multitude of factors. The altitude is an important factor in controlling landslides, but indirectly by means of other geomorphological parameters (fragmentation, declivity, relief energy, etc.).

The highest frequency of landslides is found in the gap 200-250 m altitude $(37,84 \%)$, largely corresponding to slopes, while the gap $250-300 \mathrm{~m}$ has a lower frequency of only $26,83 \%$, followed by the gap $150-200 \mathrm{~m}$ altitude with a frequency of $21,53 \%$. An insignificant frequency holds the gap $350-400 \mathrm{~m}(2,42 \%)$ or under $100 \mathrm{~m}$ altitude $(2,23 \%)$, where the interfluvial peaks and meadows are.

Depending on the inclination of hills, landslides are distributed almost entirely between $5-25^{\circ}(99,86 \%)$. Of these, $48,23 \%$ is located on land with a slope of 10 $15^{\circ}$ and $33,49 \%$ is on land with a slope between $5-10^{\circ}$ (tab.2).

Tab. 2. Area and landslide frequency by slope category in the Stemnic river basin

\begin{tabular}{|c|c|c|}
\hline Classes & Area (ha) & Percentage (\%) \\
\hline$\leq 1^{\circ}$ & 0,00 & 0.00 \\
\hline $1-3^{\circ}$ & 1,64 & 0,128 \\
\hline $3-5^{\circ}$ & 8,17 & 0,639 \\
\hline $5-10^{\circ}$ & 428,18 & 33,488 \\
\hline $10-15^{\circ}$ & 614,02 & 48,023 \\
\hline $15-25^{\circ}$ & 224,87 & 17,587 \\
\hline$>25^{\circ}$ & 1,72 & 0,135 \\
\hline Total & $\mathbf{1 2 7 8 , 6 0}$ & $\mathbf{1 0 0 , 0}$ \\
\hline
\end{tabular}


When interpreting the distribution of landslide based on depth of fragmentation, it is found that the maximum frequency of the processes is specific to sectors characterized by values of vertical fragmentation between $75-100 \mathrm{~m}$ $(49,35)$ and 50-75 $\mathrm{m}(25,89 \%)(\mathrm{tab} .3)$.

Tab. 3. Area and landslide frequency by fragmentation category in the Stemnic river basin

\begin{tabular}{|c|c|c|}
\hline Classes & Area (ha) & Percentage (\%) \\
\hline$\leq 50 \mathrm{~m}$ & 57,58 & 4,503 \\
\hline $50-75 \mathrm{~m}$ & 331,09 & 25,895 \\
\hline $75-100 \mathrm{~m}$ & 630,93 & 49,345 \\
\hline $100-125 \mathrm{~m}$ & 233,68 & 18,276 \\
\hline$>125 \mathrm{~m}$ & 25,33 & 1,981 \\
\hline Total & $\mathbf{1 2 7 8 , 6}$ & $\mathbf{1 0 0}$ \\
\hline
\end{tabular}

Depending on the slope exposure in the basin, most sliding bodies are present on the slope which faces north and west that correspond, generally, to the cuesta front. Arable lands are classified in a very high susceptibility class (tab. 4).

Tab. 4. Classification of the land use classes in susceptibility classes

\begin{tabular}{|l|l|l|}
\hline Classes & Susceptibility & \multicolumn{1}{c|}{ Use } \\
\hline Class 4 & Very high & Arable \\
\hline Class 3 & High & Pastures, complex agriculture \\
\hline Class 2 & Medium & Forests, orchards, vineyards \\
\hline Class 1 & Low & Deforestation, settlements \\
\hline
\end{tabular}

In the case of precipitation classes, precipitations of more than $600 \mathrm{~mm}$ fall to the very high susceptibility class. Taking into account the medium multiannual quantities between $535,5 \mathrm{~mm}$ in Vaslui and $510,9 \mathrm{~mm}$ in Negreşti, we classify the basin in the third high susceptibility class.

The suffusion is done either chemically - chemical suffusion, either by water, which displaces and transport fine rock particles - hydrodynamic suffusion (Mac, 1986). Chemical suffusion occurs in a larger period of time and is related to dissolution. It removes salts deposited on rock pores, eliminates carbonates, transforms and takes over carbonate particles in solution. After the creation of free spaces, the fine particles migrate and underground openings widen until the surface openings are created.

Hydrodynamic suffusion is differentiated by the type of groundwater flow, in: slow hydrodynamic suffusion, under natural groundwater flow conditions, and fast hydrodynamic suffusion, when the groundwater flow is influenced by human intervention, such as excavations for construction. 
In the basin area, generally on the slopes built from medium-textured deposits, the groundwater flow has obvious effects on modelling by displacing and driving fine particles. Associating hydrodynamic suffusion with chemical suffusion contributes to the occurrence of characteristic shapes on the slopes: underground drainage canals, suffusion funnels and chimneys. When these forms emerge, the suffusion processes are correlated with the compaction processes. Such forms do occur subordinated in the Stemnic river basin.

Subsidence occurs due to undermining the basis of a mass of rocks due to the lack of support on which it is placed. Within the Stemnic river basin, such processes are specific to structural plates or to edges of sliding cornices, contributing to their sloping (Fig. 4). If clays of marls sit on sands that appear on the slopes of some valleys or in the ravines that deepened greatly, well contoured collapses occur.

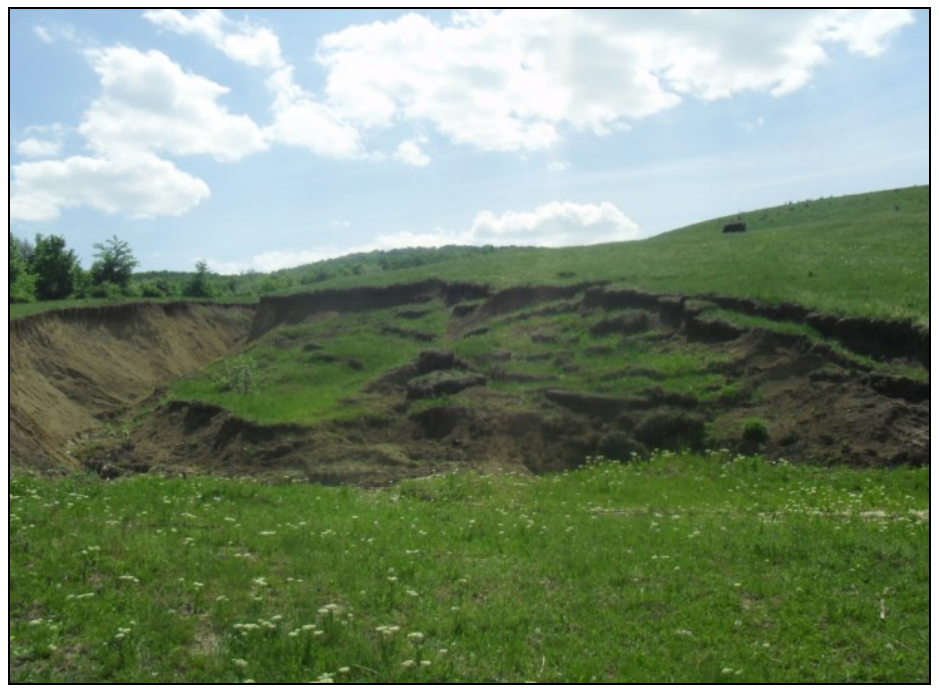

Fig. 4. Collapse of the sliding corniche

More obvious within the basin are the collapses caused by the man-action of procuring construction material from the base of some slopes. By extracting a large quantity of material (generally clay, sand and sandstone), in time, a large stack of material is undermined, which then collapses.

The corresponding erosion and the lateral erosion do not have any visible effects on the major and minor riverbed, which occur especially during floods. Consequences occur when the water flows over the banks of the minor riverbed and enter the meadow. In many cases, overflows lead to a thin layer of alluvial deposits in the major riverbed. Observations along the minor bed indicate a 
stability of river banks, the lack of visible thresholds and the riverbed keeping its natural course (fig. 5). Along the main riverbed there are still some puddles or abandoned canals, invaded by hygrophilous vegetation. The major riverbed has artificial drainage canals, and downstream from Bălteni, also protection dams until the confluence with Bârlad River.

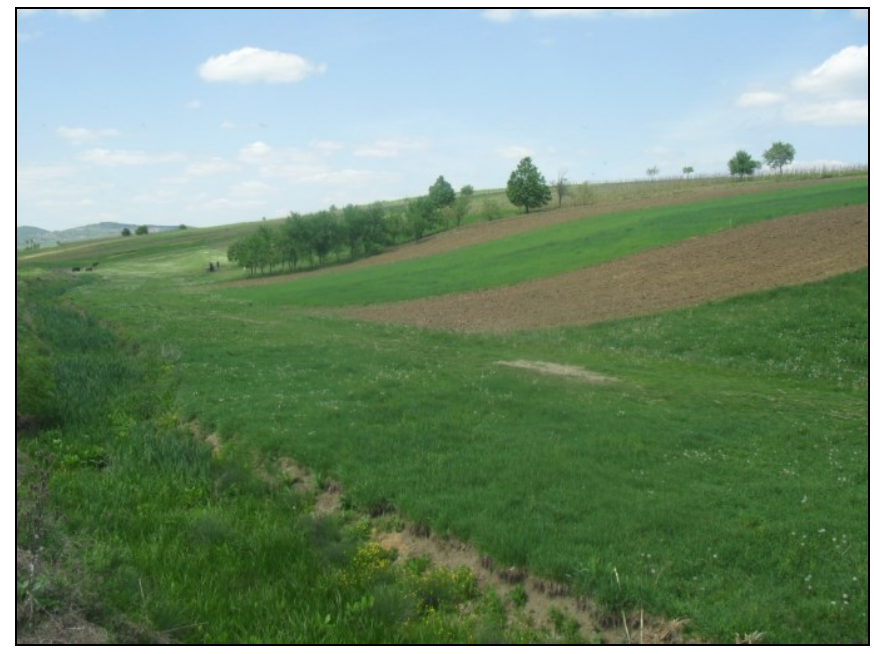

Fig. 5. Meadow of Stemnic River upstream from Buda

The processes of sedimentation / siltation are caused by the transportation of dragged or suspended alluvium, particularly during flood waves. They carry the largest amounts of suspended solid materials, due to the rise in the slope erosion processes and to the increase in transport capacity of the river while increasing the liquid flow.

For the Central Moldavian Plateau, I. Ioniţă (2000) says that the annual sedimentation rhythm is of $2,9 \mathrm{~cm} /$ year, arguing that the moderate values are determined by a number of features of the landscape, especially by the predominant clay lithology and by the significant degree of coverage with forest vegetation

In the Stemnic river basin there was a single artificial accumulation of proportions close to Bălteni, whose dam gave away due to the torrential rains in 1996; the alluvium was fixed by the vegetation. 


\section{Conclusions}

Among the geomorphological processes that occur within the basin, we consider that landslides and deep erosion processes pose a serious risk; these may affect agricultural lands and some households in the human settlements.

Landslides are stabilised or semi-stabilised, but they may reactivate in case of large amounts of precipitations. Generally, there is no risk for human settlements, but they can affect the areas with natural pastures, crops, access roads.

In case of deep erosion, the major risk is caused by large torrential organisms inside villages (as it is the case of Chetreşti, Albeşti) and that can affect household or other social and economic objectives.

\section{References}

Băcăuanu V. et al (1980), Moldavian Plateau. Nature. Man. Economy, Editura Ştiinţifică şi Enciclopedică, Bucharest;

Ioniță I. (2000), Cuesta relief in the Moldavian Plateau, Editura Corson, Iaşi;

Ioniță I. (2000), Formation and evolution of Ravines Bârladului Plateau, Editura Corson, Iaşi;

Ioniță I. (2007), Critical erosion season in the Bârladului Plateau, in vol. ,, The impact of the hydro-climatic and pedo-geomorphological risks on the environment in the Bârladului Basin”, Editura Universității „Al. I. Cuza”, Iași;

Jeanrenaud P., Saraiman A. (1995), Geology of Central Moldavia between Siret and Prut Rivers, Editura Universităţii „Al. I. Cuza”, Iaşi;

Larion Daniela (2004), The climate of Vaslui Municipality, Editura Terra Nostra, Iaşi;

Mac I. (1986), Elements of dynamic geomorphology, Editura Acadimei R.S. România, Bucharest;

Moțoc M., Munteanu S., Băloiu V., Stănescu P., Mihai Gh, (1975), Soil erosion and control methods, Editura Ceres, Bucharest;

Pujină D. (1997), Research on some sliding processes of agricultural lands in Bârladului Plateau and contributions to their landscaping, Thesis summary, "Gh. Asachi" Technical University, Iaşi;

Rădoane Maria, Rădoane N., Ichim I., Surdeanu V. (1999), Ravines - forms, processes, evolution, Editura Presa Universitară Clujeană;

Stângă I. C. (2007), Natural hazards. Notions and concepts, Editura Universităţii „Al. I. Cuza", Iași;

Tufescu V. (1966), Natural modelling of the relief and accelerated erosion, Editura Acadimei R.S. România, Bucharest; 
